\title{
The relationships between food and energy intakes, salt content and sugar types in Egyptian fruit bats
}

\author{
L. Gerardo Herrera M. ${ }^{a}$, Ariovaldo P. Cruz-Neto ${ }^{b}$, Michał S. Wojciechowski ${ }^{c}$, \\ Paloma Larrain ${ }^{\mathrm{d}}$, Berry Pinshow ${ }^{\mathrm{d}}$, Carmi Korine ${ }^{\mathrm{d}, *}$ \\ a Estación de Biología de Chamela, Instituto de Biología, Universidad Nacional Autónoma de México, Apartado Postal 21, San Patricio, Jalisco, 48980, Mexico \\ b Departamento de Zoologia, IB, Universidade Estadual Paulista, Caixa Postal 199, 13506-900, Rio Claro, São Paulo, Brazil \\ c Department of Vertebrate Zoology, Nicolaus Copernicus University, Toruń, Poland \\ ${ }^{\mathrm{d}}$ Mitrani Department of Desert Ecology, Jacob Blaustein Institutes for Desert Research, Ben-Gurion University of the Negev, 84900 Midreshet Ben-Gurion, \\ Israel
}

\section{A R T I C L E I N F O}

\section{Article history:}

Received 29 March 2015

Accepted 27 May 2015

Handled by Danilo Russo

Available online 4 June 2015

\section{Keywords:}

Blood and urine osmolality

Compensatory feeding

Sugars

Food intake

Fruit-eating bats

\begin{abstract}
A B S T R A C T
Frugivorous animals may face an osmoregulatory challenge due to the watery nature of their food and low concentration of electrolytes therein. We examined the effects of salt content $(\mathrm{NaCl})$ and sugar type (sucrose vs. glucose) on the intake rate of dilute sugar solutions by the Egyptian fruit bat (Rousettus aegyptiacus). Increased salt content did not bring about an increase in energy intake by bats fed dilute sucrose diets and the bats did not compensate by hyperphagia to achieve the energy intake of bats fed concentrated sucrose solution without salt. Moreover, increasing salt content had a negative effect on the total energy intake of Egyptian fruit bats fed equicaloric sucrose solutions. There were no differences in hematocrit in bats fed the diets of different sucrose concentration, but plasma osmolality was higher in those bats fed more concentrated sugar solutions, and urine osmolality was higher in those fed on highsalt diets. Food and energy intake did not differ between bats that were fed dilute glucose and sucrose solutions. Our findings indicate that Egyptian fruit bats do not modulate food intake when salt content of dilute sugar solutions is increased, and that increasing salt content might constrain their food intake rate. Sugar type did not affect food intake by Egyptian fruit bats, indicating that sucrose hydrolysis alone does not limit the intake of dilute sugar nectar.
\end{abstract}

(c) 2015 Deutsche Gesellschaft für Säugetierkunde. Published by Elsevier GmbH. All rights reserved.

\section{Introduction}

Many nectar- and fruit-feeding vertebrates adjust their food intake to maintain relatively constant energy intake, thereby compensating for variations in nectar sugar content (López-Calleja et al., 1997; Levey and Martínez del Rio, 1999; McWhorter et al., 2003). However, when nectarivorous and frugivorous vertebrates are fed extremely dilute sugar solutions, food ingestion rate is limiting and they cannot compensate by hyperphagia (e.g. Nicolson and Fleming, 2003; Ramírez et al., 2005; Ayala-Berdon et al., 2008; Herrera and Mancina, 2008; Herrera et al., 2011). Several physiological reasons have been invoked to explain limitations on compensatory feeding, among them the rate of sugar hydrolysis and/or assimilation, kidney processing rates, and the cost of warming food to body temperature (Nicolson and Fleming, 2003). Sucrose and glucose

\footnotetext{
* Corresponding author. Tel.: +972 8 6596773; fax: +972 86596772

E-mail address: ckorine@bgu.ac.il (C. Korine).
}

are the two main sugars found in nectar and fruit eaten by vertebrates (Baker et al., 1998). Sucrose must first be broken down into its constituent monosaccharides glucose and fructose by intestinal enzymes (sucrase, Schondube et al., 2001), whereas glucose is directly absorbed from the small intestine into the bloodstream by both active and passive mechanisms (Tracy et al., 2007; CaviedesVidal et al., 2008). Thus, digestive processing of sucrose involves one more step than that for glucose, which might result in bats imbibing solutions containing sucrose at a slower rate than glucose solutions. Sucrose hydrolysis might decrease at low sugar concentrations, resulting in lower intestinal absorption rates compared to dilute glucose solutions (Schondube and Martínez del Rio, 2003).

Due to the watery nature of fruit pulp and floral nectar, excessive ingestion of water when feeding on a dilute sugar solution is an osmoregulatory challenge that adds a further constraint on food ingestion rates for some nectarivorous and frugivorous vertebrates, regulating the extent and magnitude of compensatory feeding (Martínez del Rio et al., 2001). For example, water overingestion in white-bellied sunbirds (Cinnyris talatala) fed very 
dilute sucrose solutions (0.07-0.1 $\left.\mathrm{moll}^{-1}\right)$ led to the excretion of more electrolytes than when the birds were fed a higher sugar concentration (Fleming and Nicolson, 2003). Large losses of electrolytes might thus limit the ingestion of dilute sugar solutions that contain only minute amounts of salts (Fleming and Nicolson, 2003). It has also been found that the intake rate of a dilute sucrose solution $\left(0.1 \mathrm{moll}^{-1}\right)$ by white-bellied sunbirds and New Holland honeyeaters (Phylidonyris novaehollandiae) was higher when salt was added $\left(20 \mathrm{mmol}^{-1} \mathrm{NaCl}\right)$ (Purchase et al., 2010). Furthermore, both species of birds had similar energy intakes when fed a dilute sucrose solution $\left(0.1 \mathrm{moll}^{-1}\right)$ with added $\mathrm{NaCl}\left(20 \mathrm{mmol}^{-1} \mathrm{NaCl}\right)$ than on salt-free solutions with a higher sucrose concentration (0.25-1 $\left.\mathrm{moll}^{-1}\right)$, indicating the occurrence of compensatory feeding when salt is added (Purchase et al., 2010). Although intake rate of dilute sugar solutions by these birds increased as the concentration of salts increased (1:1 mol NaCl: $\mathrm{KCl}$ mixtures), no difference was found between the highest salt concentrations (20 and $40 \mathrm{mmol}^{-1} \mathrm{NaCl}: \mathrm{KCl}$; Purchase et al. 2010), suggesting that the effect of increased salt content on intake rate is not additive. In contrast, food intake rate was similar in the nectarivorous Pallas's long-tongued bat, Glossophaga soricina, fed a dilute sucrose solution $\left(0.292 \mathrm{moll}^{-1}\right)$ with $\left(75 \mathrm{mmol} \mathrm{NaCll} \mathrm{l}^{-1}\right)$ or without salt, but intake rate decreased with higher salt content $\left(>150 \mathrm{mmol} \mathrm{NaCll}^{-1}\right.$; Bakken et al., 2008). Thus, ingestion rate of sugary diets by vertebrate frugivores and nectarivores might be affected by salt content but the direction of this effect needs further examination.

The diet of the Egyptian fruit bat, Rousettus aegyptiacus Linnaeus 1758 , includes fruits with very high water content (up to 90\%; Korine et al., 1998) and low Na content (Arad and Korine, 1993). Korine et al. (2006) reported that the energy intake of Egyptian fruit bats fed sucrose solutions with small amounts of $\mathrm{NaCl}\left(11 \mathrm{mmoll}^{-1}\right)$ was lower when fed a liquid diet dilute in sucrose $\left(0.256 \mathrm{moll}^{-1}\right.$; energy intake $=268-307 \mathrm{~kJ} /$ day $)$ than when fed a diet with a high sucrose content $\left(0.658 \mathrm{moll}^{-1}\right.$; energy intake $=304-364 \mathrm{~kJ} /$ day). Thus, apparently Egyptian fruit bats do not or cannot compensate in response to feeding on dilute sugar solutions by increased food intake, even when salt is added (Korine et al., 2006). However, these results are equivocal because the study was not designed to test the effects of salt on food intake rate. Given these limitations, we examined the effect of salt content and sugar type on intake rate of dilute sugar concentrations by Egyptian fruit bats.

To examine the effect of salt content on food intake we offered Egyptian fruit bats dilute and concentrated sucrose diets with low or high amounts of $\mathrm{NaCl}$ added and tested the predictions that the energy intake of bats fed a dilute sucrose diet increases with increasing salt content, and that their energy intake is similar to that of bats fed a diet with a high sugar concentration. Since water intake is inversely proportional to sugar concentration, we did not expect that energy intake from diets high in sugar concentration would be affected by salt content.

Some consequence of ingesting large volumes of water when feeding on dilute sugar diets are decreased plasma and urine electrolyte concentrations and decreased hematocrit, Hct (Arad and Korine, 1993; Martínez del Rio et al., 2001; Fleming and Nicolson, 2003; Purchase et al., 2010). Accordingly, we measured Hct, and the osmolalities of plasma $\left(P_{\mathrm{osm}}\right)$ and of urine $\left(U_{\mathrm{osm}}\right)$ of the bats in all the trials to gauge whether these were lower when bats were fed a dilute sucrose diet with low salt content.

To examine the effect of sugar type on food intake, we also measured intake rate of Egyptian fruit bats fed a dilute glucose solution with low $\mathrm{NaCl}$ content. Downs et al. (2012) in their study of Wahlberg's epauletted fruit bat (Epomophorus wahlbergi), an Old World fruit bat, showed that sucrose hydrolysis does not limit the intake of dilute sugar solutions. Accordingly, we predicted that intake rate of bats fed glucose and sucrose solutions would be the same. Since these sucrose and glucose diets had the same low salt concentration, we predicted no differences in Hct, $P_{\text {osm }}$ and $U_{\text {osm }}$ between bats consuming the two diets.

\section{Material and methods}

\section{Husbandry}

Four adult male and three non-reproductive adult female Egyptian fruit bats (body mass $\left(m_{\mathrm{b}}\right): 110-150 \mathrm{~g}$ ) were captured with mist nets in an underground parking garage in Beer Sheva, Israel, in June 2011 and were housed in an outdoor flight cage $(7 \times 3 \times 2.5 \mathrm{~m})$ on the Sede Boqer Campus of Ben-Gurion University of the Negev $\left(30^{\circ} 51^{\prime} \mathrm{N}, 34^{\circ} 47^{\prime} \mathrm{E}\right.$; $476 \mathrm{~m}$ above sea level) where they were habituated for 3 weeks before trials began. During this period, bats were offered an assortment of fruits such as apples and bananas ad libitum and trials began when the bats attained and maintained constant $m_{\mathrm{b}}$. During the habitation period, a male escaped and a male died and our sample size was 5 . All individuals were colormarked for identification and all were released at their site of capture at the end of the experiments. All experiments were conducted under permit BGU-R-06-2009 (to BP) of the Animal Care and Ethics Committee of the Ben-Gurion University. The study was carried out under permit number 17510 from the Israel Nature and Parks Authority.

\section{Trial protocol}

Experimental trials were preceded by two days of habituation to the trial conditions, followed by a 2-day experiment. Bats were habituated to an ambient temperature $\left(T_{\mathrm{a}}\right)$ of $30^{\circ} \mathrm{C}$, which is $1{ }^{\circ} \mathrm{C}$ below their average lower critical temperature (Korine and Arad, 1993). The bats were offered a liquid diet (see below) that varied in sugar content, ad libitum. At the start of the habituation period we transferred the bats to individual cages, which were covered with black cloth hoods, in a controlled-environment room $\left(T_{\mathrm{a}}=30 \pm 1^{\circ} \mathrm{C}\right)$ with a $12 \mathrm{~h}$ light: $12 \mathrm{~h}$ dark cycle. On the first day of habituation, we fed the bats the same mixed fruit diet that they received in the outdoor flight cage. On the following day, bats were fed the same liquid diet as they were in the experimental trial. Starting from the second day of the trial, food intake was measured each morning. Between trials, we returned the bats to the flight cage for two weeks of recovery.

\section{Diets}

We prepared five diets based on Korine et al. (2006; Table 1). The sugar and protein concentrations were within the range found in fruits eaten by Egyptian fruit bats in the wild (Korine et al., 1998). Diets were low in sucrose and low or high in $\mathrm{NaCl}$ (LSLNa or LSHNa, respectively), high in sucrose and low or high in $\mathrm{NaCl}$ (HSLNa or HSHNa, respectively), and low in glucose and low in $\mathrm{NaCl}$ (LGLNa). The LSLNa diet $\left(82.4248 \mathrm{~kJ} 100 \mathrm{ml}^{-1}\right)$ and LGLNa diet

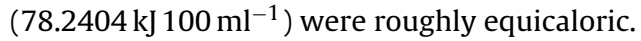

\section{Trial design}

Each bat received all diets on separate trails in a random order. At 18:00 h on each night of a trial, weighed amounts of food $( \pm 0.01 \mathrm{~g}$; Scout Pro, Ohaus Corporation, Florham Park, NJ, USA) were placed in two feeders (a transparent plastic bowl $16 \times 7 \mathrm{~cm}$ ) inside each cage and removed at 06:00 h the following morning when they were reweighed. For the rest of the day, (i.e. during their rest phase) the bats did not have access to food. The difference between the masses was assumed to be the quantity of food 
Table 1

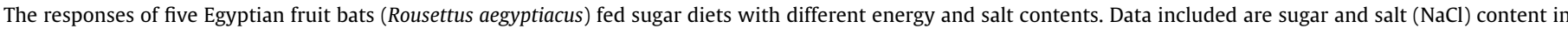

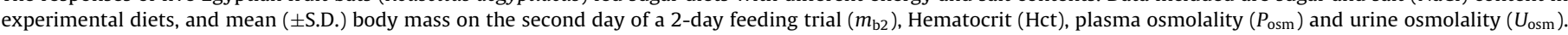

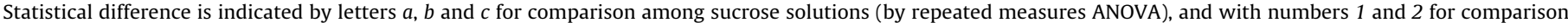

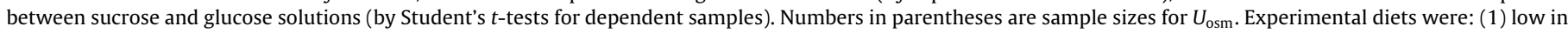
sucrose and low (LSLNa) or (2) high in $\mathrm{NaCl}$ (LSHNa), (3) high in sucrose and low (HSLNa) or (4) high in $\mathrm{NaCl}$ ( $\mathrm{HSHNa}$ ), or (5) low in glucose and NaCl (LGLNa).

\begin{tabular}{|c|c|c|c|c|c|c|c|c|}
\hline \# & Diet & Sugar $^{*}\left(\mathrm{moll}^{-1}\right)$ & $\mathrm{NaCl}\left(\mathrm{mmoll}^{-1}\right)$ & Soy protein $\left(\mathrm{gl}^{-1}\right)$ & $m_{\mathrm{b} 2}(\mathrm{~g})$ & Hct (\%) & $P_{\mathrm{osm}}\left(\mathrm{mmoll}^{-1}\right)$ & $U_{\mathrm{osm}}\left(\mathrm{mmoll}^{-1}\right)$ \\
\hline 1 & LSLNa & 0.204 & 11 & 7.23 & $142.1 \pm 25.2$ & $54.4 \pm 0.9^{\mathrm{a} 1}$ & $281 \pm 2.9^{\mathrm{ab} 1}$ & \\
\hline 2 & LSHNa & 0.204 & 40 & 7.23 & $140.2 \pm 20.4$ & $57.8 \pm 1.2^{\mathrm{a}}$ & $279.8 \pm 4.3^{\mathrm{a}}$ & $401 \pm 82.1(4)$ \\
\hline 3 & HSLNa & 0.584 & 11 & 7.23 & $142.6 \pm 24.5$ & $55.8 \pm 1.5^{\mathrm{a}}$ & $284 \pm 1.4^{\mathrm{b}}$ & $144 \pm 20.5(2)$ \\
\hline 4 & HSHNa & 0.584 & 40 & 7.23 & $140.2 \pm 16.7$ & $56.4 \pm 3.5^{\mathrm{a}}$ & $289.6 \pm 3.8^{c}$ & $494.5 \pm 0.5(2)$ \\
\hline 5 & LGLNa & 0.388 & 11 & 7.23 & $139.2 \pm 23.8$ & $58.5 \pm 2.9^{1}$ & $291.6 \pm 4.3^{2}$ & $167(1)$ \\
\hline
\end{tabular}

Sucrose or glucose.

eaten after correcting for evaporation and food drippings. To control for evaporation, we placed three feeders with the same amount of food in the controlled environment room in cages without bats and weighed them along with the bat feeders. To control for food drippings, we placed absorbent paper on the bottom of the cage and weighed the paper at the beginning and end of each trial and considered the difference in mass as a proxy of food lost by dripping.

At $04: 00 \mathrm{~h}$ on the last day of the experiment, we placed plasticlined paper on the bottom of the cages. Every 15 minutes, for 4 hours, we collected freshly voided urine by aspiration with glass pipettes. The urine samples were placed in Eppendorf tubes that were immediately cooled in an ice bath and then refrigerated until analysis later that day. We did not collect urine that was contaminated with feces. $U_{\text {osm }}$ was measured in duplicate, whenever possible, using a freezing point depression osmometer (Osmette II, Precision Systems, Natick, MA, USA). Bats were weighed $( \pm 0.01 \mathrm{~g})$ at 18:00 on the first and second days of being fed the experimental diets, and their fractional change in $m_{\mathrm{b}}$ was calculated:

$m_{\mathrm{b}} \mathrm{FC}=\frac{m_{\mathrm{b}} \text { day } 2-m_{\mathrm{b}} \text { day } 1}{m_{\mathrm{b}} \text { day } 1}$.

\section{Blood analysis}

Blood samples were drawn from a wing vein into standard Naheparinized $0.75 \mu$ l capillary tubes (Fisher Scientific, Pittsburgh, PA, USA) at the end of the experiment at 08:00 h. Blood samples were centrifuged for 5 minutes with a refrigerated table-top centrifuge (Hettich Mikro 22R, Tuttelingen, Germany), Hct was determined and $P_{\text {osm }}$ was analyzed in duplicate with the abovedescribed osmometer.

\section{Statistical analyses}

Volumetric food intake, energy intake, Hct, $P_{\text {osm }}, U_{\text {osm }}$ and $m_{\mathrm{b}} \mathrm{FC}$ were compared among sucrose-salt diets using single factor (diet) repeated-measures analyses of variance (RM-ANOVA). When the result of RM-ANOVA was significant $(P<0.05)$, we applied Tukey's HSD tests for repeated measures (Purchase et al. 2010). The assumption of sphericity was met for all comparisons done with RM-ANOVAs (Mauchly test). Except for $U_{\text {osm }}$, for which no data were obtained from bats feeding on the LSLNa diet, we compared the same above-listed variables between dilute solutions of sucrose and glucose using Student's $t$-tests for dependent samples. Data are reported as means \pm S.D., and null hypotheses were rejected at $\alpha=0.05$. Statistical analyses were done with STATISTICA 7 (StatSoft, Tulsa, Oklahoma).

In light of our small sample size, we also used a randomized resampling test (computed with " $R$ ") in addition to the parametric statistical tests. We created 1000 data sets, assuming that each diet group followed a normal distribution, with a mean and S.D. from the original data set. We used a linear mixed effects model with bat ID as a random factor, and diet as a fixed factor and ran it several

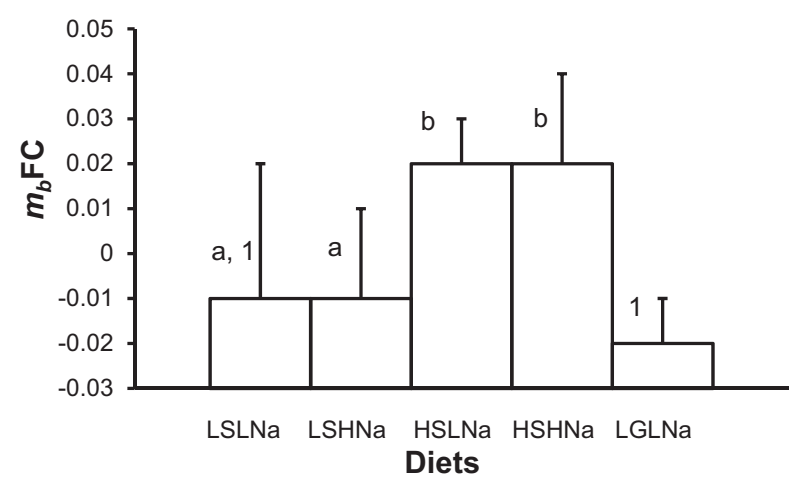

Fig. 1. Mean $\left( \pm\right.$ S.D.) fractional change in body mass $\left(m_{\mathrm{b}} \mathrm{FC}\right)$ between the first and second days of a trial in which five Egyptian fruit bats (Rousettus aegyptiacus) were fed sugar diets with different energy and salt contents. Statistically significant difference is indicated by different letters $a$ and $b$ for comparison among sucrose solutions (by repeated measures ANOVA), and with the number 1 for comparison between sucrose and glucose solutions (by Student's $t$-tests for dependent samples). Experimental diets were: $\operatorname{LSLNa}=0.204 \mathrm{moll}^{-1}$ sucrose, $11 \mathrm{mmoll}^{-1} \mathrm{NaCl}$; LSHNa $=0.204 \mathrm{moll}^{-1}$ sucrose, $40 \mathrm{mmoll}^{-1} \mathrm{NaCl}$; HSLNa $=0.584 \mathrm{moll}^{-1}$ sucrose, $11 \mathrm{mmol} \mathrm{l}^{-1} \mathrm{NaCl}$; HSHNa $=0.584 \mathrm{moll}^{-1}$ sucrose, $40 \mathrm{mmoll}^{-1} \mathrm{NaCl}$; LGLNa $=0.388 \mathrm{moll}^{-1}$ glucose, $11 \mathrm{mmoll}^{-1} \mathrm{NaCl}$.

times, with a different dependent variable each time: $m_{\mathrm{b}} \mathrm{FC}$, volumetric food intake and energy intake (Wood, 2006). We repeated this procedure 1000 times with the 1000 data sets that we created, and for each dependent variable we calculated the percentage of $\alpha$ values that were lower than 0.05 . We considered the data to be significant if $\geq 70 \%$ of estimated $\alpha$ values were lower than 0.05 (Wetzels et al., 2011).

\section{Results}

\section{Body mass changes}

There were significant differences in $m_{\mathrm{b}} \mathrm{FC}$ among sucrose diets $\left(F_{3,12}=6.1, P=0.01\right.$; Fig. 1$)$; bats feeding on the HSLNa and HSHNa diets had significantly higher fractional increases than bats feeding on the LSHNa diet ( $P=0.02$ and $P=0.03$, respectively), and we observed a trend toward a higher proportional increase than in bats eating the LSHNa diet ( $P=0.06$ and 0.09 , respectively). On average, bats feeding on the LSLNa and LSHNa diets lost $m_{\mathrm{b}}$, whereas bats feeding on the HSLNa and HSHNa diets gained $m_{\mathrm{b}}$ (Fig. 1). No difference in $m_{\mathrm{b}} \mathrm{FC}$ was found between bats fed the LGLNa and LSLNa diets $\left(t_{4}=1.5, P=0.2\right.$; Fig. 1$)$. The randomized resampling test for the $m_{\mathrm{b}} \mathrm{FC}$ showed that $76 \%$ of $\alpha$ values were lower than 0.05 .

\section{Food and energy intakes}

We found significant differences in mean volumetric food intake $\left(F_{3,12}=4.6, P=0.02\right.$; Fig. 2$)$ only between the LSLNa and the HSHNa diets $(P=0.01)$. The randomized resampling test for volumetric 


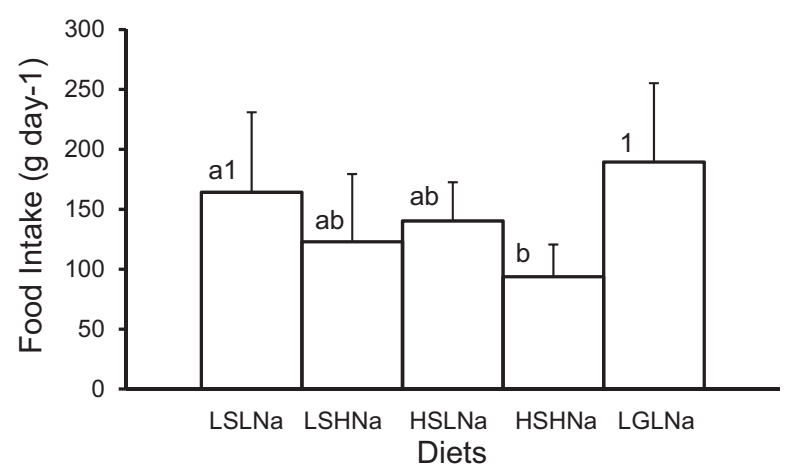

Fig. 2. Mean ( $t$ S.D.) food intake by five Egyptian fruit bats (Rousettus aegyptiacus) fed sugar diets with different energy and salt contents. Statistically significant difference is indicated by different letters $a$ and $b$ for comparison among sucrose solutions (by repeated measures ANOVA), and with the number 1 for comparison between sucrose and glucose solutions (by Student's $t$-tests for dependent samples). Experimental diets were: $\operatorname{LSLNa}=0.204 \mathrm{moll}^{-1}$ sucrose, $11 \mathrm{mmoll}^{-1} \mathrm{NaCl}$; LSHNa $=0.204 \mathrm{moll}^{-1}$ sucrose, $40 \mathrm{mmol} \mathrm{l}^{-1} \mathrm{NaCl}$; $\mathrm{HSLNa}=0.584 \mathrm{moll}^{-1}$ sucrose, $11 \mathrm{mmoll}^{-1} \mathrm{NaCl}$; HSHNa $=0.584 \mathrm{moll}^{-1}$ sucrose, $40 \mathrm{mmoll}^{-1} \mathrm{NaCl}$; LGLNa $=0.388 \mathrm{moll}^{-1}$ glucose, $11 \mathrm{mmoll}^{-1} \mathrm{NaCl}$.

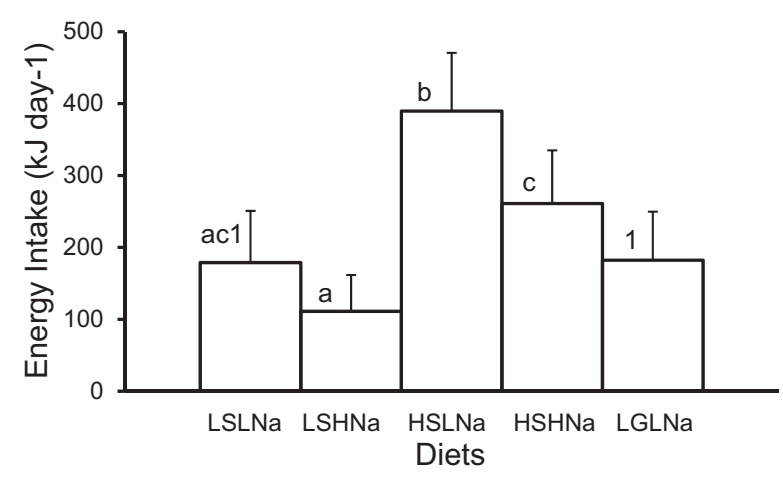

Fig. 3. Mean ( \pm S.D.) energy intake by five Egyptian fruit bats (Rousettus aegyptiacus) fed sugar diets with different energy and salt contents. Statistically significant difference is indicated by different letters $a, b$ and $c$ for comparison among sucrose solutions (by repeated measures ANOVA), and with the number 1 for comparison between sucrose and glucose solutions (by Student's $t$-tests for dependent samples). Experimental diets were: $\operatorname{LSLNa}=0.204 \mathrm{moll}^{-1}$ sucrose, $11 \mathrm{mmoll}^{-1} \mathrm{NaCl}$; LSHNa $=0.204 \mathrm{moll}^{-1}$ sucrose, $40 \mathrm{mmoll}^{-1} \mathrm{NaCl}$; $\mathrm{HSLNa}=0.584 \mathrm{moll}^{-1}$ sucrose, $11 \mathrm{mmoll}^{-1} \mathrm{NaCl}$; HSHNa $=0.584 \mathrm{moll}^{-1}$ sucrose, $40 \mathrm{mmoll}^{-1} \mathrm{NaCl}$; LGLNa $=0.388 \mathrm{moll}^{-1}$ glucose, $11 \mathrm{mmoll}^{-1} \mathrm{NaCl}$.

food intake showed that only $60 \%$ of $\alpha$-values were lower than 0.05 indicating that the sample size was too small. There were significant differences in energy intake among bats feeding on the sucrose diets $\left(F_{3,12}=29.7, P<0.0001\right.$; Fig. 3$)$. Energy intake was lower in bats eating the LSLNa diet than bats feeding on the HSLNa $\operatorname{diet}(P=0.0002)$; it was lower in bats fed the LSHNa diet than those fed the HSLNa $(P=0.0002)$ and the HSHNa diets $(P=0.003)$; and it was lower in bats fed the HSHNa diet than those fed the HSLNa diet $(P=0.004)$. There were no significant differences in mean food and energy intakes between bats fed LSLNa and LGLNa diets $\left(t_{4}=1.7\right.$, $P=0.1$, and $t_{4}=1, P=0.3$, respectively; Figs. 2 and 3 ). The randomized resampling test for the energy intake also revealed that $99 \%$ of $\alpha$ values were lower than 0.05 .

Hct, $\mathrm{P}_{\text {osm }}$ and $\mathrm{U}_{\text {osm }}$

There were no differences in Hct among bats fed sucrose diets $\left(F_{3,12}=0.7, P=0.5\right.$; Table 1$)$, but there were significant differences in $P_{\text {osm }}\left(F_{3,12}=16.8, P=0.0001\right.$; Table 1$)$. Bats fed the HSHNa diet had higher $P_{\text {osm }}$ than bats fed the other diets $(P<0.01)$, and bats on the HSLNa diet had higher $P_{\text {osm }}$ than on the LSHNa diet $(P=0.03)$.
There were no differences in Hct between bats fed the LSLNa and LGLNa diets $\left(t_{4}=1.5, P=0.1\right.$; Table 1$)$, but $P_{\text {osm }}$ was higher in bats fed the LGLNa than the LSLNa diet $\left(t_{4}=3.5, P=0.02\right.$; Table 1$)$. We were unable to obtain urine samples from all bats, which reduced the sample size and precluded statistical comparisons of $U_{\mathrm{osm}}$. However, bats feeding on high salt diets produced more concentrated urine than when fed a diet low in salt content (Table 1).

\section{Discussion}

We found no support for our prediction that Egyptian fruit bats increase their intake of dilute sucrose diets as $[\mathrm{NaCl}]$ is increased, and thus balance their energy intake. In contrast, energy intake rate was lower when $[\mathrm{NaCl}]$ was increased in both dilute and concentrate sucrose diets. We also found no evidence that energy intake rate of a glucose diet is higher than that of a roughly equicaloric sucrose diet.

\section{Salt content and food intake}

Food intake by Egyptian fruit bats fed on the LSLNa diet provided $50 \%$ less energy than the HSLNa diet, indicating that, as in other plant-eating bats fed dilute sugar solutions (Ramírez et al., 2005; Ayala-Berdon et al., 2008; Herrera and Mancina, 2008; Herrera et al., 2011), they do not compensate by increasing food intake. Intake of the dilute sugar diet did not increase when dietary [ $\mathrm{NaCl}]$ was increased: energy intake of bats fed the LSHNa diet was 70\% lower than when they were fed the HSLNa diet. These differences in energy intake between bats fed dilute and concentrated sugar solutions were accompanied by differences in $m_{\mathrm{b}} \mathrm{FC}$. Body mass in bats fed the HSHNa and HSLNa diets increased, whereas the bats lost $m_{\mathrm{b}}$ when fed the LSLNa and LSHNa diets. Egyptian fruit bats decreased their energy intake when feeding on both dilute and concentrated sucrose solutions when $[\mathrm{NaCl}]$ was increased; specifically bats ingested 36\% less energy on the LSHNa diet than the LSLNa diet, and 36\% less energy on the HSHNa diet than the HSLNa diet. Our results indicate that increased $[\mathrm{NaCl}]$ was associated to decreased intake of sugar solutions by Egyptian fruit bats. The highest $[\mathrm{NaCl}]$ used in our study $\left(40 \mathrm{mmol}^{-1}\right)$ is lower than that used in a study of the nectarivorous Pallas's long-tongued bat, in which no negative effect of salt on food intake of sucrose solution was found ( $70 \mathrm{mmol}^{-1} \mathrm{NaCl}$; Bakken et al., 2008). However, when food $[\mathrm{NaCl}]$ was $>150 \mathrm{mmol}^{-1}$, Pallas's long-tongued bat also decreased its intake rate (Bakken et al., 2008). We are not aware of other studies that have explored the effect of salt content of the intake of sugar solutions by nectar and fruit eating bats.

The kidneys of fruit and nectar eating bats are well adapted to processing large amounts of water but their ability to increase $U_{\text {osm }}$ is moderate compared to insectivorous bats (Studier et al., 1983a; Studier et al., 1983b; Arad and Korine, 1993; Herrera et al., 2001; Pilosof and Herrera, 2010). When salt content of their diet was increased to $40 \mathrm{mmoll}^{-1}, U_{\text {osm }}$ of Egyptian fruit bats increased up to $\sim 500 \mathrm{mmoll}^{-1}$, a value that is close to the maximum value $\left(555 \mathrm{mmol}^{-1}\right.$ ) recorded in this bat when they feed on fruit with very low water content (12\%; Arad and Korine, 1993). The upper limit on the intake of sugar solutions containing significant amounts of salt might be limited in the Egyptian fruit bat by its kidney's ability to concentrate urine. Salt processing by animals might be energetically expensive (Gutiérrez et al., 2011) and salt excretion might limit food intake and energy gain.

The $P_{\text {osm }}$ of Egyptian fruit bats feeding on all the diets were within the range found in a wild population of Egyptian fruit bats (275-297 $\mathrm{mmoll}^{-1}$; Korine et al., 1999). $P_{\mathrm{osm}}$ did not differ between bats fed the two dilute sugar diets and approached the value measured in bats fed a normal fruit diet $\left(280.9 \mathrm{mmoll}^{-1}\right.$; 
Arad and Korine, 1993). Bats in the LSHNa diet ingested almost three times $\left(296.7 \pm 136.8 \mathrm{mg} \mathrm{NaCl} \mathrm{day}^{-1}\right)$ the salt ingested when they were fed the LSLNa diet $\left(108.2 \pm 43.9 \mathrm{mg} \mathrm{NaCl} \mathrm{day}^{-1}\right)$, and they produced hyperosmotic urine, implying that excess salt was eliminated to maintain $P_{\mathrm{osm}}$. $P_{\mathrm{osm}}$ was higher in the HSHNa diet when Egyptian fruit bats ingested large amounts of salt $\left(226.3 \pm 65 \mathrm{mg} \mathrm{NaCl} \mathrm{day}^{-1}\right)$; however, even then, bats maintained $P_{\text {osm }}$ below the highest value reported for the species when waterrestricted (297.9 $\mathrm{mmoll}^{-1}$; Arad and Korine, 1993) by excreting hyperosmotic urine.

Mean Hct of Egyptian fruit bats was similar to that previously reported for the species in the wild (Korine et al., 1999) and under several hydration regimes (Arad and Korine, 1993). Egyptian fruit bats maintained Hct independent of dietary [ $\mathrm{NaCl}]$, implying robust plasma volume maintenance in the face of changing water and salt intakes.

\section{Sugar type and food intake}

Sucrose must be broken down in the intestine into glucose and fructose, and glucose is absorbed mostly via a passive, paracellular pathway in Egyptian fruit bats (Tracy et al., 2007). In addition to the burden of processing excess water, food intake might be limited by decreased sucrase activity (Schondube and Martínez del Rio, 2003). However, as found in an other Old World frugivorous bat (Downs et al., 2012), the intake of dilute sugar solutions by Egyptian fruit bats in the present study was not limited by sucrase activity as both sucrose and glucose solutions were processed at the same rate. In addition, Amitai et al. (2010) found that Egyptian fruit bats metabolize glucose and sucrose at about the same rate when fed concentrated sugar solutions (30\% mass/mass). Although energy concentration of the sucrose diet was slightly higher than that of the glucose diet, we consider that this difference does not affect our main findings. In fact, energy intake was $~ 9 \%$ higher on the glucose than the sucrose diet but this difference was barely not significant $(P=0.1)$.

In summary, Egyptian fruit bats did not increase food intake rate when salt was added to their diet of dilute solutions was not affected by sugar type. Our sample size was small but our study, along with observations made on Pallas's long-tongued bat (Bakken et al., 2008), indicate that, in contrast to birds (Purchase et al., 2010; Purchase et al., 2013), intake of sugary solutions by plant-eating bats is negatively affected when salt is added. However, we do not reject the possibility that lower $[\mathrm{NaCl}]$ than the concentration used in our study might benefit their intake rate of dilute sugar solutions, or that Egyptian fruit bats might respond positively to the addition of other electrolytes. Further examination of the effect of salt on the intake rate of sugary diets in other frugivorous and nectarivorous bats before arguing the existence of contrasting patterns with avian species.

\section{Acknowledgements}

LGHM was supported by sabbatical grants from CONACYT (\#146770) and UNAM-DGAPA (\#1404), and by a research grant from CONACYT (\#100035). APCN was supported by a travel grant from The Graduate Program of the State University of São Paulo (PROPG - UNESP) and by a research grant from FAPESP (\#08/57687$0)$. We thank Dr. Miri Ben-Hamo for her assistance with the statistical analysis. This is publication no. 872 of the Mitrani Department of Desert Ecology.

\section{References}

Amitai, O., Holtze, S., Barkan, S., Amichai, E., Korine, C., Pinshow, B., Voigt, C.C., 2010. Fruit bats (Pteropodidae) fuel their metabolism rapidly and directly with exogenous sugars. J. Exp. Biol. 213, 2693-2699.
Arad, Z., Korine, C., 1993. Effect of water restriction on energy and water balance and osmoregulation of the fruit bat Rousettus aegyptiacus. J. Comp. Physiol. B 163, 401-405

Ayala-Berdon, A., Schondube, J.E., Stoner, K.E., Rodriguez-Peña, N., Martínez del Rio, C., 2008. The intake responses of three species of leaf-nosed Neotropical bats. J. Comp. Physiol. B 178, 477-485.

Bakken, B.H., Herrera, M.L.G., Carroll, R.M., Ayala-Berdón, J., Schondube, J.E., Martínez del Rio, C., 2008. A nectar-feeding mammal avoids body fluid disturbances by varying renal function. Am. J. Physiol. Renal Physiol. 295, F1855-F1863.

Baker, H.G., Baker, I., Hodges, S.A., 1998. Sugar composition of nectar and fruits consumed by birds and bats in the tropics and subtropics. Biotropica 30, 559-586.

Caviedes-Vidal, E., Karasov, W.H., Chediack, J.G., Fasulo, V., Cruz-Neto, A.P., Otani, L., 2008. Paracellular absorption: a bat breaks the mammal paradigm. PLoS One 3, e1425.

Downs, C.T., Mqokeli, B., Singh, P., 2012. Sugar assimilation and digestive efficiency in Wahlberg's epauletted fruit bat (Epomophorus wahlbergi). Comp. Biochem. Physiol. A 161, 344-348.

Fleming, P.A., Nicolson, S.W., 2003. Osmoregulation in an avian nectarivore, the Whitebellied sunbird (Nectarinia talatala): response to extremes of diet concentration. J. Exp. Biol. 206, 1845-1854.

Gutiérrez, J.S., Masero, J.A., Abad-Gómez, J.M., Villegas, A., Sánchez-Guzmán, J.M. 2011. Understanding the energetic costs of living in saline environments: effects of salinity on basal metabolic rate, body mass and daily energy consumption of a long-distance migratory shorebird. J. Exp. Biol. 214, 829-835.

Herrera M., L.G., Mancina G., C.A., 2008. Sucrose hydrolysis does not limit food intake by Pallas's long-tongued bats. Physiol. Biochem. Zool. 81, 119-124.

Herrera M., L.G., Martínez del Río, C., Braun, E., Hobson, K., 2001. Renal structure in Neotropical bats: using stable isotopes to explore relationships between diet and morphology. Isot. Environ. Health Stud. 37, 1-11.

Herrera M., L.G., Osorio M., J., Mancina G., C.A., 2011. Ammonotely in a neotropical frugivorous bat as energy intake decreases. J. Exp. Biol. 21, 3775-3781.

Korine, C., Arad, Z., 1993. Effect of water restriction on temperature regulation of the fruit bat Rousettus aegyptiacus. J. Therm. Biol. 18, 61-69.

Korine, C., Izhaki, I., Arad, Z., 1998. Comparison of fruit syndromes between the Egyptian fruit-bat Rousettus aegyptiacus and birds in East Mediterranean habitats. Acta Oecol. 19, 147-153.

Korine, C., Zinder, O., Arad, Z., 1999. Diurnal and seasonal changes in blood composition of the free-living Egyptian fruit bat (Rousettus aegyptiacus). J. Comp. Physiol. B 169, 280-286.

Korine, C., Vatnick, I., van Tets, I.G., Pinshow, B., 2006. The influence of ambient temperature, energy and protein content of the food on nitrogenous excretion in the Egyptian fruit bat (Rousettus aegyptiacus). Physiol. Biochem. Zool. 79, 957-964.

Levey, D.J., Martínez del Rio, C., 1999. Test, rejection, and reformulation of a chemical reactor-based model of gut function in a fruit-eating bird. Physiol. Zool. 72, 369-383.

López-Calleja, M., Bozinovic, V.F., Martínez del Rio, C., 1997. Effects of sugar concentration on hummingbird feeding and energy use. Comp. Biochem. Physiol. A $118,1291-1299$.

Martínez del Rio, C., Schondube, J.E., McWhorter, T.J., Herrera, L.G., 2001. Intake responses in nectar feeding birds: digestive and metabolic causes, osmoregulatory consequences, and coevolutionary effects. Am. Zool. 41, 902-915.

McWhorter, T.J., Martínez del Rio, C., Pinshow, B., 2003. Modulation of ingested water absorption by Palestine sunbirds: evidence for adaptive regulation. J. Exp. Biol. 206, 659-666.

Nicolson, S.W., Fleming, P.A., 2003. Energy balance in the Whitebellied sunbird Nectarinia talatala: constraints on compensatory feeding, and consumption of supplementary water. Funct. Ecol. 17, 3-9.

Pilosof, S., Herrera M., L.G., 2010. Variability in urine concentration and fecal water content of bats in a tropical deciduous forest. J. Mammal. 91, 580-585.

Purchase, C., Fleming, P.A., Nicolson, S., 2010. Added salt helps sunbirds and honeyeaters maintain energy balance on extremely dilute nectar diets. J. Comp. Physiol. B 180, 1227-1234

Purchase, C., Nicolson, S.W., Fleming, P.A., 2013. Salt intake and regulation in two passerine nectar drinkers: white-bellied sunbirds and New Holland honeyeaters. J. Comp. Physiol. B 183, 501-510.

Ramírez P., N., Herrera M., L.G., Mirón M., L., 2005. Physiological constraint to food ingestion in a New World nectarivorous bat. Physiol. Biochem. Zool. 78, $1032-1038$

Schondube, J.E., Martínez del Rio, C., 2003. Concentration-dependent sugar preferences in nectar-feeding birds: mechanisms and consequences. Funct. Ecol. 17, 445-453.

Schondube, J.E., Herrera M., L.G., Martínez del Rio, C., 2001. Diet and the evolution of digestion and renal function in phyllostomid bats. Zoology 104, 59-73.

Studier, E.H., Boyd, B.C., Feldman, A.T., Dapson, R.W., Wilson, D.E., 1983a. Renal function in the Neotropical bat, Artibeus jamaicensis. Comp. Biochem. Physiol. A 74, 199-209.

Studier, E.H., Wisniewski, S.J., Feldman, A.T., Dapson, R.W., Boyd, B.C., Wilson, D.E., 1983b. Kidney structure in Neotropical bats. J. Mammal. 64, $445-452$.

Tracy, C., McWhorter, T.J., Korine, C., Wojciechowski, M.S., Pinshow, B., Karasov, W.H., 2007. Absorption of sugars in the Egyptian fruit bat (Rousettus aegyptiacus): a paradox explained. J. Exp. Biol. 210, 1726-1734.

Wetzels, R., Matzke, D., Lee, M.D., Rouder, J.N., Iverson, G.J., Wagenmakers, E.J., 2011. Statistical evidence in experimental psychology an empirical comparison using 855 t tests. Perspect. Psychol. Sci. 6, 291-298.

Wood, S.N., 2006. Generalized Additive Models: An Introduction with R. CRC Press. 